\title{
Effect of varying crustal thickness on CHAMP geopotential data.
}

P. T. Taylor (1), K. I. Kis (2), R. R. B. von Frese (3), J. V. Korhonen (4), G. Wittmann (5), H. R. Kim (3), L. V. Potts (6)

(1) NASA/GSFC, Geodynamics Branch, (2) Geophysical and Environmental Physics Research Group of the Hungarian Academy of Sciences, (3) Department of Geological Science, Ohio State University, (4) Geological Survey of Finland, (5) MOL Hungarian Oil and Gas Co., (6) Laboratory for Space Geodesy and Remote Sensing Research, The Ohio State University.

To determine the effect of crustal thickness variation on satellite-altitude geopotential anomalies we compared two regions of Europe with vastly different values, Central/Southern Finland and the Pannonian Basin. Crustal thickness exceeds $62 \mathrm{~km}$ in Finland and is $<26 \mathrm{~km}$ in the Pannonian Basin. Heat-flow maps indicate that the thinner and more active crust of the Pannonian Basin has a value nearly three times that of the Finnish Svecofennian Province. Ground based gravity mapping in Hungary shows that the free-air gravity anomalies across the Pannonian Basin are near 0 to $+20 \mathrm{mGal}$ with shorter wavelength anomalies from +40 to $<+60 \mathrm{mGal}$ and some 0 to $>-20 \mathrm{mGal}$. Larger anomalies are detected in the mountainous areas. The minor value anomalies can indicate the isostatic equilibrium for Hungary (the central part of the Pannonian Basin). Gravity data over Finland are complicated by de-glaciation. CHAMP gravity data $(400 \mathrm{~km})$ indicates a west-east positive gradient of $>4 \mathrm{mGal}$ across Central/Southern Finland and an ovoid positive anomaly $(\sim 4 \mathrm{mGal})$ quasi-coincidental with the magnetic anomaly traversing the Pannonian Basin. CHAMP magnetic data $(425 \mathrm{~km})$ reveal elongated semicircular negative anomalies for both regions with South-Central Finland having larger amplitude $(<-6 \mathrm{nT})$ than that over the Pannonian Basin, Hungary ( $<-5 \mathrm{nT})$. In both regions subducted oceanic lithosphere has been proposed as the anomalous body. 


\title{
First Announcement
}

\section{2nd CHAMP Science Meeting}

\author{
GeoForschungsZentrum Potsdam
}

September 1-4, 2003

\section{General Information}

About 1.5 years after the 1st CHAMP Science Meeting took place in Potsdam, a second meeting will be held on September 1-4, 2003 at the GeoForschungsZentrum Potsdam (GFZ). The meeting shall stimulate a broad discussion within the international science community, especially among the CHAMP data and product users, on the exploitation and application of CHAMP data.

It is planned to publish conference proceedings in a reviewed international journal or, as the proceedings of the 1st CHAMP Science Meeting, in the Springer geosciences series - details later on.

For the Organizing Committee:

Christoph Reigber, CHAMP Project Director

GF z. Department_ 1 Back

Originator Christoph Reigber

Mar 26. 2003. webacmin A.Helm 


\section{GFZ Potsdam, Department 1}

\section{The CHAMP Mission}

Project Director: Prof. Christoph Reigber

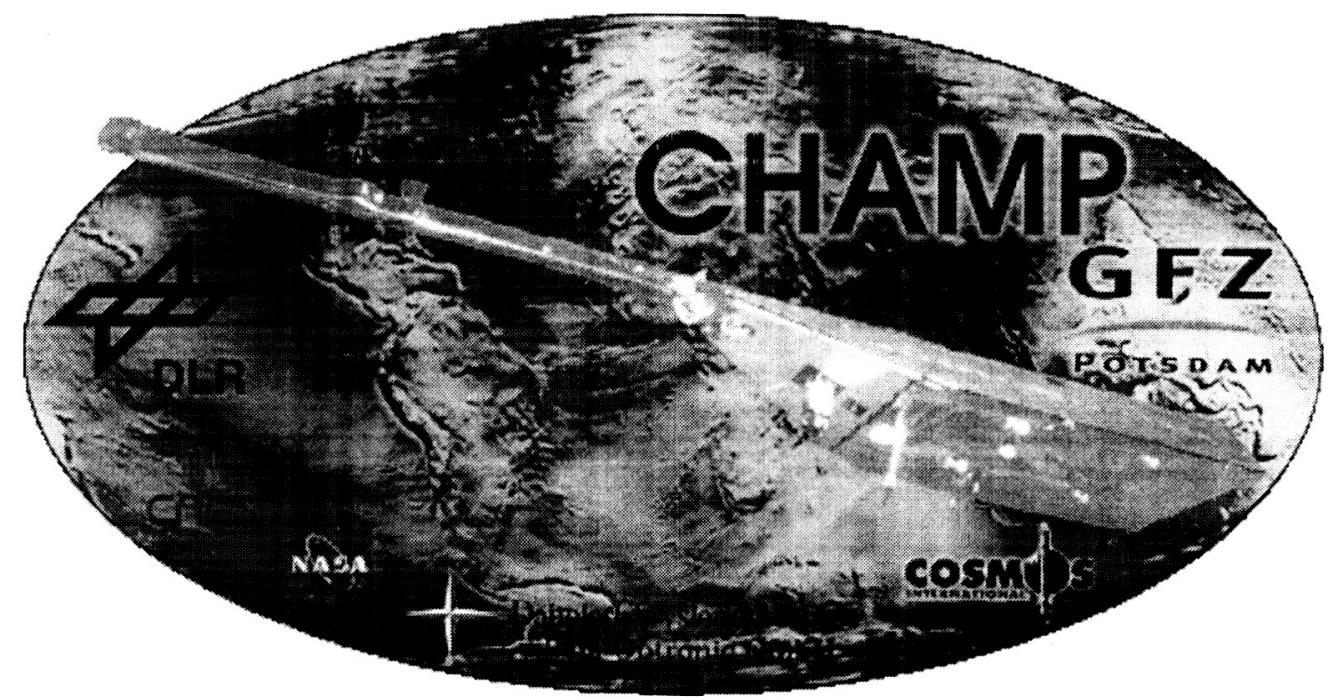

\section{News}

- CHAMP Mission Elapsed Time:

1096 days, 22 hours and 56 minutes

- CHAMP satellite in healthy condition; July 16, 2003

- Today CHAMP is celebrating his 3rd birthday. On 12:33 UTC CHAMP will enter into the 16958th revolution around the Earth. CHAMP is showing an extremly good performance and the mission has provided until now

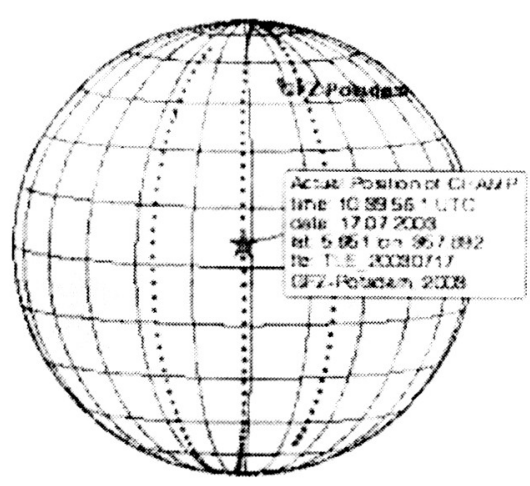

(Try SHIF Treload frame to update plot)

almost 3 million highly 
valuable scientific products on the Earth's gravity field, magnetic field and atmosphere. We wish CHAMP a long life and hope that he will continue to deliver uninterrupted data series for the benefit of Earth Sciences; July 15, 2003

\section{CHAMP related meetings}

sep -4.2003 Second

CHAMP Science Meeting

ned a Geoforschungszentrum

Potsdam

History of CHAMP related meetings

\section{News Orgmator: Ch. Reigber \\ Last update of news: 10 Juy 1508 go to older news for further infomation \\ contact.champ@gfz-potsdam.de \\ Visit \\ CHAMP Orbit Counter

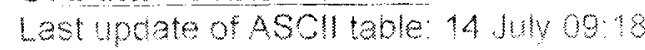 \\ CHAMP Announcement of \\ Opportunity \\ CHAMP Sample Data Set \\ CHAMP Current Orbit Data \\ CHAMP Data Center (ISDC) \\ CHAMP Videoclips \\ CHAMP Picture Gallery \\ CHAMP Online Available \\ Documents}

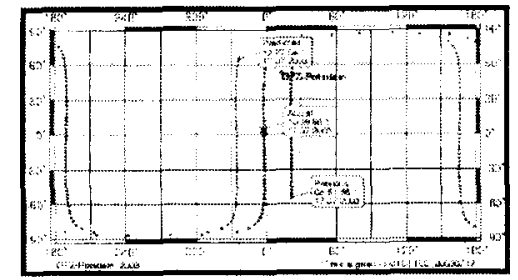

Actual ground track plot

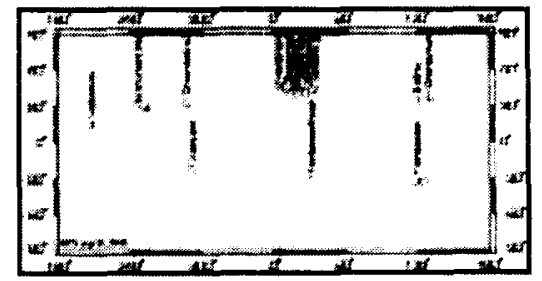

SLR tracking of CHAMP

104 SLR passes in Juy 2003

\section{Introduction}

CHAMP (CHAllenging

Minisatellite Payload) is a

German small satellite mission

\section{Contents}

Background

Science \& Mission 
for geoscientific and atmospheric research and applications, managed by GFZ. With its highly precise, multifunctional and complementary payload elements (magnetometer, accelerometer, star sensor, GPS receiver, laser retro reflector, ion drift meter) and its orbit characteristics (near polar, low altitude, long duration) CHAMP will generate for the first time simultaneously highly precise gravity and magnetic field measurements over a 5 years period. This will allow to detect besides the spatial variations of both fields also their variability with time. The CHAMP mission will open a new era in geopotential research and will become a significant contributor to the Decade of Geopotentials.

In addition with the radio occultation measurements onboard the spacecraft and the infrastructure developed on ground, CHAMP will become a pilot mission for the preoperational use of space-borne GPS observations for atmospheric and ionospheric research and applications in weather prediction and space weather monitoring.
Background

Project \& Partners

Organisation \&

Responsibilities, Partners

Science Objectives

Earth Gravity Field

Recoverery, Earth Magnetic

Field Recoverery, Electric

Field Investigations, Atmospheric Limb Sounding, lonosphere Sounding

Science Results

First Earth Gravity Field

Model Including CHAMP

Tracking Data, First

Occultation Measurements

Satellite System

Satellite, Subsystems, Science Instruments

Mission \& Orbit

Orbit Characteristics, Launch, Nominal Orbit, Mission Phases, Prediction

Products

Operation \& Data

Ground Segment, Mission Operation System (MOS), Science Operation System (SOS), Science Data System (SDS)

References \& More

References, Picture Gallery, Links

Contact

Contact Information, Addresses of Key Personnal 


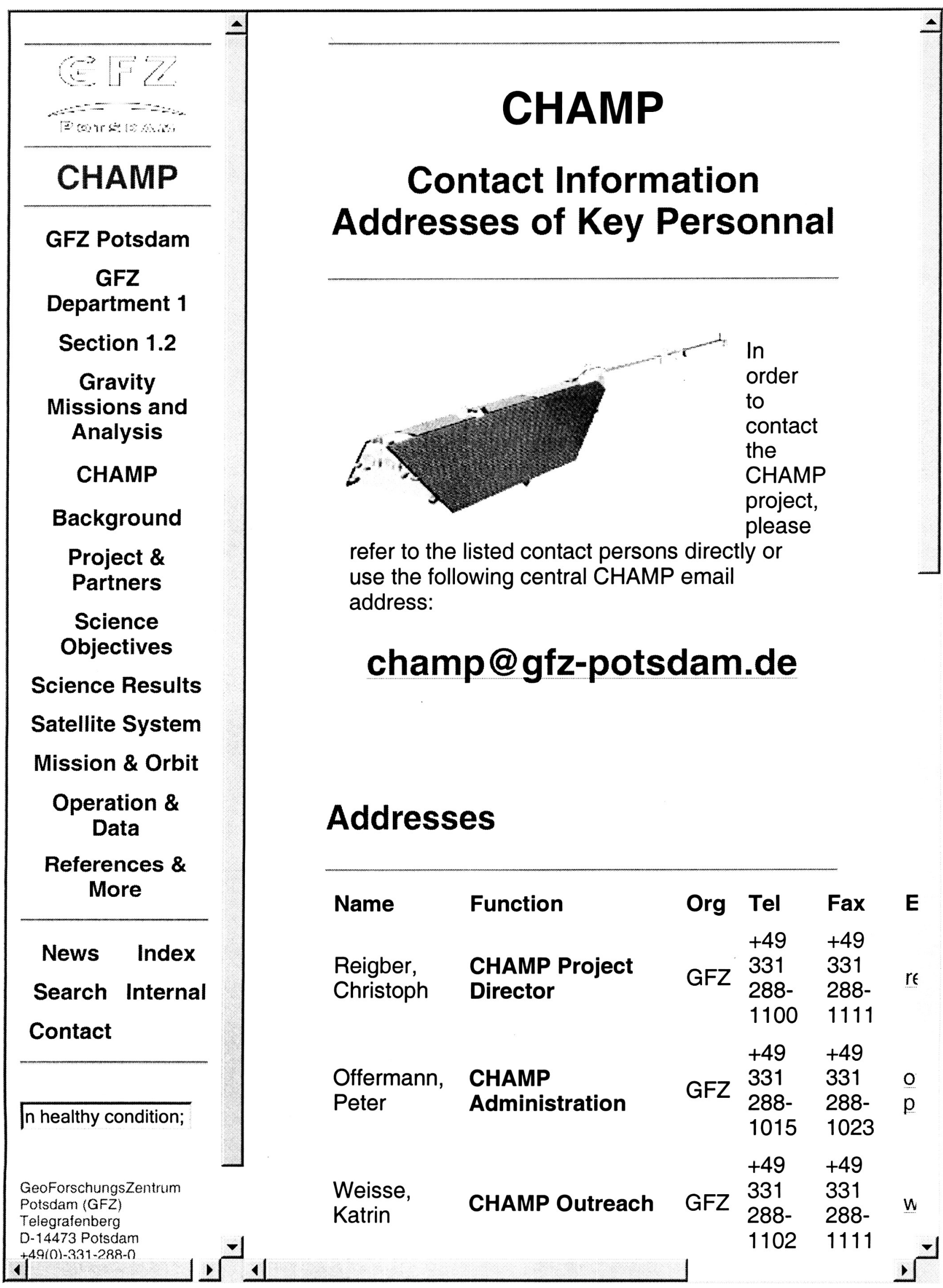

